\title{
Na Mira do Anti-fúngico Ideal
}

\author{
MARGARIDA MEIRELES 1 e FATIMA NORBERTO 2
}

\section{INTRODUÇÃO}

Apesar de estarmos rodeados de fungos, na maior parte das situações o nosso sistema imunitário é eficaz na defesa contra as infecções causadas por este organismo oportunista. No entanto, é possível que alguns fungos proliferem na pele causando irritação sem causa aparente, as membranas mucosas (como a boca, e a vagina) podem ser afectadas pelo crescimento exagerado de fungos e, infecç̧ões sistémicas de origem fúngica, podem mesmo dar origem a situações clínicas de muita gravidade.

As infecções fúngicas em humanos têm o nome de micoses e podem ser do tipo superficial (como as dermatofitoses) ou sistémico (tais como as candidíases e as criptococoses).

Nos últimos 20 anos verificouse um aumento da incidência de infecções fúngicas sistémicas com alguma gravidade. Estas infecções ocorrem mais frequentemente em indivíduos imunodeprimidos (devido a transplantes de órgãos, quimioterapia tumoral ou infecção pelo Vírus da Imunodeficiência Humana VIH), nos tratados com antibacterianos de largo espectro ou ainda naqueles que foram sujeitos a técnicas invasivas (catéteres e sondas). As espécies patogénicas mais comuns são Cryptococcus neoformans, Aspergillus fumigatus e algumas espécies do género Mucor.

Por causa das muitas semelhanças entre as células humanas e as células fúngicas, já que ambas são eucarióticas e têm um metabolismo semelhante, tem sido difícil e lento o desenvolvimento de anti-fúngicos que sejam simultaneamente eficazes e pouco tóxicos para o homem

\section{SUBSTÂNCIAS ANTI-FÚNGICAS}

Os primeiros agentes usados como anti-fúngicos foram o iodeto de potássio, sais de metais pesados, derivados benzóicos e fenólicos, e, mais tarde sais de amónio quaternário, [1] e o tolnaftato, apenas potente contra dermatófitos [2]. A era da quimioterapia antimicósica teve início com a descoberta da nistatina (Figura $1,(1))$ a que se seguiu a anfotericina B(Figura 1,(2)), ambas pertencentes ao gupo dos polienos. A nistatina é usada apenas para uso tópico, por causa da sua elevada toxicidade a nível sistémico. A anfotericina B tem sido usada com sucesso por mais de duas décadas mas a sua toxicidade, especialmente renal, faz com que ela seja usada actualmente só em último recurso. De facto, este fungicida, é o único polieno usado para as micoses sistémicas e é ainda hoje indicado para o tratamento das micoses profundas nos doentes imunossuprimidos. Os efeitos colaterais podem ser reduzidos recorrendo aos lipossomas e dispersões coloidais.

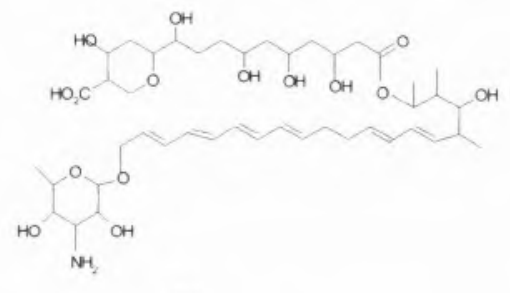

(1)
A griseofulvina (Figura 2,(3)) foi introduzida na década de 50 como o primeiro anti-fúngico oral eficaz, não sendo útil quando por via tópica. Trata-se de um agente que permite obter bons resultados no tratamento de dermatófitos responsáveis por muitas micoses superficiais.

Mais recentemente, a 5-fluorocitosina (Figura 2, (4)), uma pirimidina fluorada sintética, foi considerada eficaz no tratamento da criptococose, da candidiase e provavelmente da aspergilose. O seu uso tem sido porém limitado devido ao desenvolvimento de resistência fúngica.

O conhecimento da função fenacilimidazole (Figura 3, (5)) levou à descoberta de benzilaminas substi-

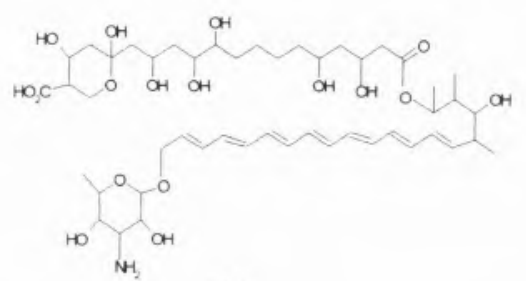

(2)

Fig. 1 - (1) nistatina ; (2) anfotericina B

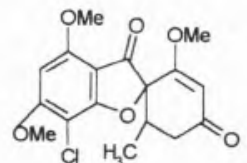

(3)

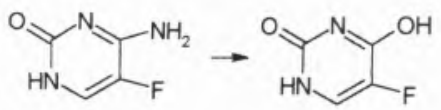

(4)
(4)
Fig. 2 - (3) griseofulvina; (4) 5-fluorocitosina (4') 5-fluorouracilo
(5)

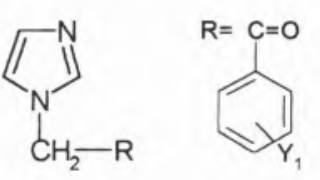

(6)

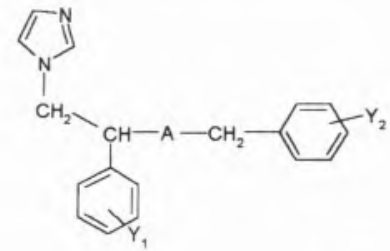

(7)
$\mathrm{A}=\mathrm{NH}$

$\mathrm{A}=\mathrm{O} \quad$ (7a) $\mathrm{Y}_{1}=2,4-\mathrm{Cl}_{2} \mathrm{Y}_{2}=2,4 \mathrm{Cl}_{2}$

(7b) $\mathrm{Y}_{1}=2,4-\mathrm{Cl}_{2} \mathrm{Y}_{2}=4 \mathrm{Cl}$

(7c) $\mathrm{Y}_{1}=2,4-\mathrm{Cl}_{2} \mathrm{Y}_{2}=2,6 \mathrm{Cl}_{2}$ 
tuídas (6) e em seguida da classe dos éteres benzílicos (7) em cuja classe se contam o miconazole (7a), o econazole (7b) e o isoconazole (7c) [3]. Estes compostos constituiram um grande avanço do ponto de vista clínico no tratamento de micoses superficiais e, no caso do miconazole, de micoses sistémicas.

Decidiu então avançar-se para a substituição de um dos aneis aromáticos por um anel heterocíclico e foi assim que surgiu o cetoconazole (Figura 4,(8)) [3]. A actividade antifúngica do cetoconazole assemelhase à do miconazole. Aquando da administração tópica este composto revelou-se bastante activo no tratamento de infecções por dermatófitos e, na administração oral o cetoconazole, apresenta bastante actividade contra a tricofitose e a candidíase. Todos estes azois são porém rápida e extensamente metabolisados, excepto o cetoconazole que apesar de tudo ainda não é o anti-fúngico ideal pois continua a ter efeitos colaterais não desejados como, por exemplo, a inibição da síntese de testosterona.

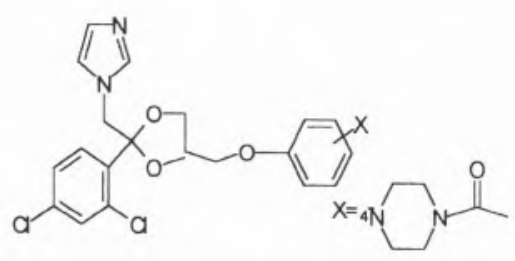

Fig. 4 - (8) cetoconazol

A partir da década de 80 , a Companhia farmacêutica Janssen iniciou então um estudo promovendo uma série de variações estruturais que incluiram a inserção das funções dioxolano (9), ditiolano (10), tetrahidrofurano (11) e alcoois terciários (12) (Figura 5) [3]. Estes derivados demonstraram boa eficácia in vitro mas não in vivo.

Para uma boa eficácia in vivo é necessário que o agente seja absorvido no tracto gastro-intestinal, e chegue ao local de acção sem sofrer metabolização hepática. Ora uma gran-

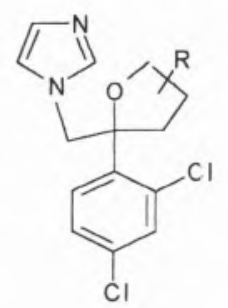

(9)

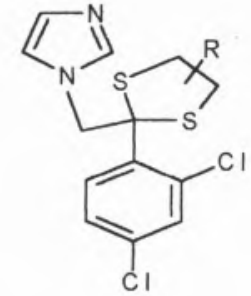

(10)

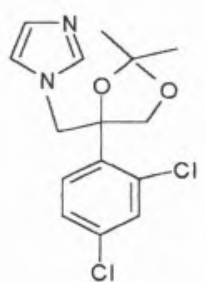

(11)

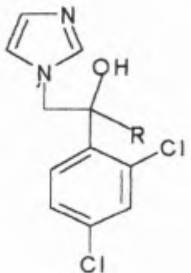

(12)

Fig. 5 - Variações estruturais em derivados de imidazol

de percentagem dos derivados de imidazole são metabolizados antes de entrar na circulação sistémica, resultando numa baixa biodisponibilidade a nível oral e baixos níveis plasmáticos. Além disso, são muito lipofílicos e, cerca de $90 \%$ deles, aparecem ligados a proteínas plasmáticas o que resulta em níveis circulantes muito baixos da forma activa, não ligada. Em virtude do anel de imidazole ser responsável pela labilidade destes fármacos relativamente a reacções de metabolização, foram sintetizados vários derivados mono e bistriazole com o objectivo de conseguir não só mais resistência relativamente à metabolização hepática como também menor lipofilia. Foi numa destas tentativas que se chegou à estrutura do fluconazole (13) (Figura 6), [4], um bistriazole da classe dos alcoois terciários com um substituinte arilo difluorado, que o tornou muito pouco lipossolúvel, ao contrário de todos os outros descritos até ao momento.

Os ensaios clínicos iniciais foram realizados com doentes com candidíase vulvovaginal, tendo sido

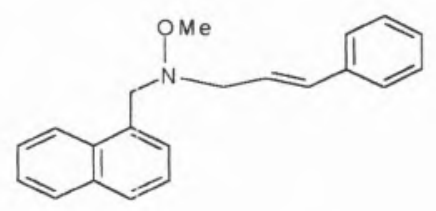

(14) observados excelentes resultados clínicos (100\% de curas). O fluconazole apresentou também 100\% de curas em pacientes com sindroma de imunodeficiência adquirida sofrendo de candidíase orofaríngea. Além de activo contra infecções por

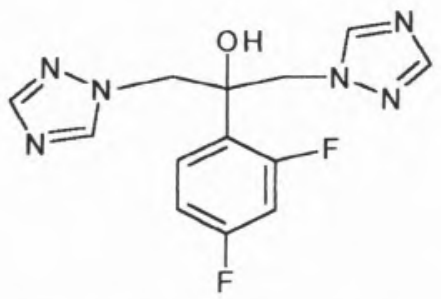

Fig. 6 - (13) Fluoconazol

Candida este derivado revelou-se de imensa valia em infecções por Cryptococcus, Aspergillus e mesmo dermatófitos.

Em 1984 surgiu uma nova classe de anti-fúngicos, as alilaminas, cujos exemplos em uso incluem a naftifina (14) e a terbinafina (15) (Figura 7).

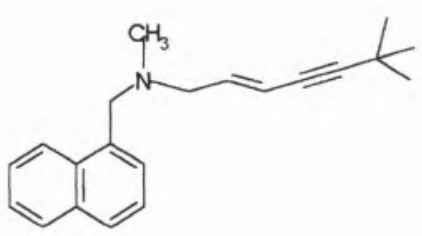

(15) 


\section{O MECANISMO DE ACÇÃO DOS ANTI-FÚNGICOS}

As várias classes de anti-fúngicos actuam de diferentes formas, afectando diversos aspectos do metabolismo das células fúngicas, com maior ou menor interferência no metabolismo da célula do hospedeiro.

A 5-fluorcitosina actua através do seu produto de desaminação, o 5 fluoruracilo (Figura 2,(4)), que é incorporado no RNA em vez do uracilo, ou é convertido em ácido 5-F-2'desoxiuridílico, o qual inibe a síntese do timidilato sintetase celular, afectando assim também a síntese de DNA. De facto, apesar de esta substância anti-fúngica ser menos tóxica que a anfotericina B teve sempre que ser usada prudentemente pois poderia ter efeitos carcinogénicos [5].

A acção anti-fúngica das substâncias pertencentes ao grupo dos polienos baseia-se no facto de a sua ligação ao ergosterol presente na membrana plasmática das células dos fungos, resultar na desorganização dessa membrana, afectando necessáriamente a sua função biológica [6]. Dessa ligação resulta um aumento da permeabilidade da membrana com consequente dissipação do gradiente de protões, perda do conteúdo citoplasmático e morte celular. A eficiência da ligação desta substância ao ergosterol da membrana plasmática das células fúngicas, é cerca de 10 vezes superior ao da ligação ao colesterol das células animais. No entanto, mesmo assim, este fungicida apresenta efeitos colaterais adversos tais como a nefrotoxicidade.

A griseofulvina em fungos susceptíveis, liga-se ao RNA e a proteínas associadas aos microtúbulos resultando a sua acção na inibição da síntese de ácidos nucleicos e na alteração da formação dos microtúbulos [7].Além de dar origem a células anormais o fármaco pode inibir a mitose de células de animais e de plantas causando mitose multipolar e formação de núcleos anormais.

O conteúdo em ergosterol das membranas celulares das células dos fungos, diferencia estas células das

células animais em que o colesterol é o esterol envolvido na regulação da permeabilidade das membranas. Ambos os esterois são sintetizados de uma maneira semelhante a partir do acetil coenzima A (Figura 8) [8].

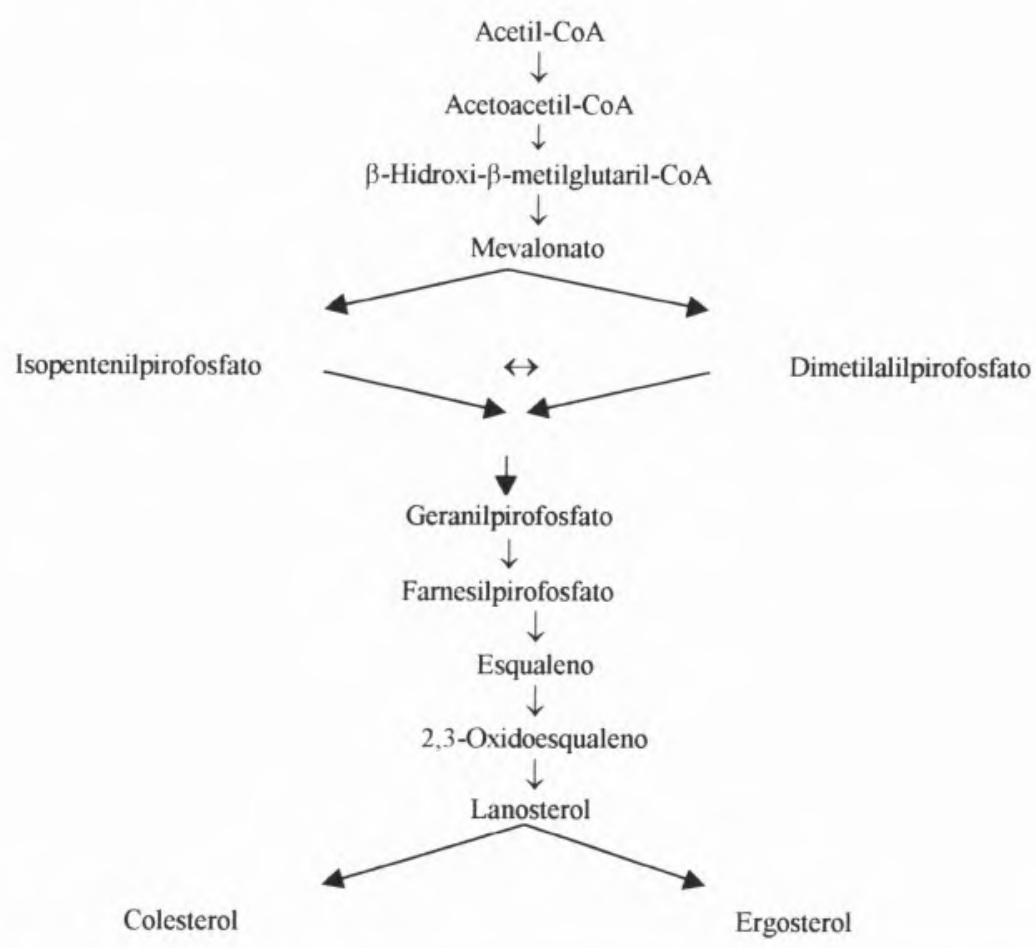

Fig. 8 - Via sintética dos esterois

Essa síntese tem lugar em diferentes locais da célula: a transformação de acetato em mevalonato é realizada na fracção microssomal enquanto a via que dá origem ao esqualeno a partir do mevalonato é realizada no citoplasma; a conversão do esqualeno em ergosterol e colesterol é realizada de novo nos microssomas e esta é a primeira parte da via que requer oxigénio. As vias que conduzem ao ergosterol e ao colesterol são comuns até à formação de lanosterol. A remoção do grupo metilo ligado ao átomo de carbono na posição 14 do lanosterol também é comum embora não ocorra necessariamente pela mesma ordem (Figura 9).

Até à data ainda não foram purificados todos os enzimas mas, as evidências disponíveis parecem indi- car que embora os enzimas dos mamíferos e dos fungos /leveduras catalisem as mesmas interconversões, eles não são necessáriamente idênticos e são portanto passíveis de inibição selectiva. 


\section{Lanosterol}

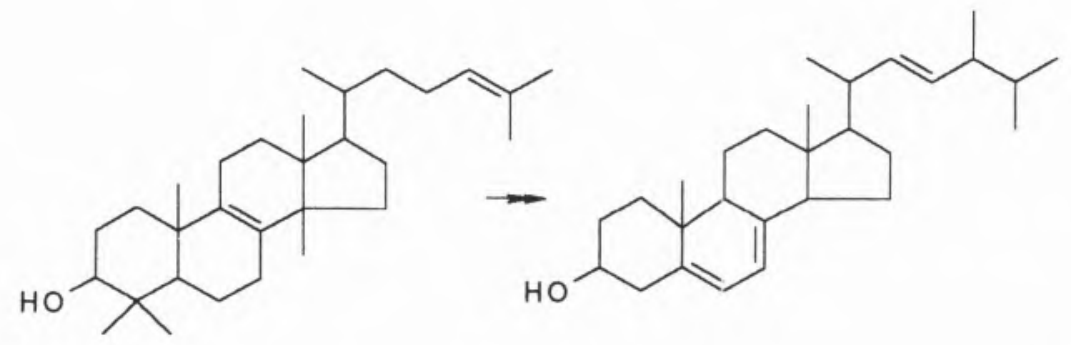

Fig. 9 - Relação entre ergosterol e lanosterol
Os derivados do imidazole (por exemplo econazole, miconazole, e cetoconazole), levam ao aumento da permeabilidade da membrana em células fúngicas susceptíveis aos fármacos, sendo também potentes inibidores da biossíntese do ergosterol [11].

Estudos comparativos feitos em células de fígado de rato e células de $C$. albicans, mostraram que a dose dos derivados de imidazole necessária para influenciar a sintese de colesterol em fígado de rato é pelo menos 6 vezes superior àquela

\section{Ergosterol}

capaz de inibir a síntese de ergosterol em C. albicans. De um modo semelhante a síntese de colesterol numa fracçâo subcelular de fígado de rato é cerca de 20-70 vezes menos sensível ao cetoconozole ou miconazole do que o é a síntese de ergosterol em fracções semelhantes obtidas de C. albicans [12].

A inibição da síntese de ergosterol em células de fungos coincide com uma acumulação de $14 \alpha$-metilesterois, indicativa de uma interacção do fármaco com o sistema do $14 \alpha$-metildesmetilase. Este é
Tabela 1. Algumas micoses superficiais comuns no homem

\begin{tabular}{lll}
\hline Doença & Área afectada & Agente causal comum \\
\hline Tinea capitis & cabeça & $\begin{array}{l}\text { Dermatófitos: Microsporum spp } \\
\text { e Tricophyton spp }\end{array}$ \\
\hline Tinea corporis & corpo & idem \\
\hline Tinea pedis & pé & Tricophyton spp \\
\hline Perionycomicose & cuticulas & Leveduras tipo Candida spp \\
\hline Candidiase vaginal & Vagina & $\begin{array}{l}\text { Candida albicans, e outras, e } \\
\text { Torulopsis glabrata }\end{array}$
\end{tabular}

Tabela 2. Algumas micoses sistémicas

\begin{tabular}{ll}
\hline Doença & Agente causal \\
\hline Candidiase sistémica e mucocutânea & Candida albicans e outras spp \\
\hline Aspergilose ( menos comum) & Aspergillus fumigatus e outras spp \\
\hline Histoplasmose & Histoplasma capsulatum \\
\hline Criptococose & Cryptococcus neoformans \\
\hline
\end{tabular}

um sistema sensível ao monóxido de carbono o que indica que é necessário um sistema enzimático dependente do citocromo P-450 para iniciar a oxidação do grupo metil $14 \alpha$ do lanosterol, o percursor do ergosterol nos microssomas dos fungos.

Foi demonstrado que o miconazole e o cetoconazole afectam o citocromo P-450 em microssomas de leveduras [13]. O citocromo P450 dos microssomas de fígado de rato é muito menos sensível àquelas substâncias, o que se correlaciona bem com a baixa sensibilidade dos referidos fármacos sobre a síntese de colesterol em células de mamífero. Foi também sugerido que a acumulação dos percursores metilados nas células fúngicas tratadas com os fármacos poderia levar a alterações funcionais nas membranas e à morte celular. De facto, para além da inibição da síntese de ergosterol, está hoje razoavelmente estabelecido que os derivados de azóis também têm uma acção directa sobre as membranas fúngicas, interactuando com os grupos acilo saturados e insaturados que fazem parte das membranas. Isto pode em parte explicar a existência de certas bactérias Gram+ susceptíveis aos derivados de azóis.

\section{CONCLUSÕES}

Os últimos anos têm conduzido a grandes avanços na variedade e na toxicidade selectiva dos anti-fúngicos disponíveis no mercado. No entanto, poucos desses compostos conseguem ainda combinar as propriedades necessárias para o tratamento das graves infeç̧ões superficiais e sistémicas nomeadamente, eficácia contra os agentes causadores, e aqui assume particular importância a conhecida aquisição de resistência aos anti-fúngicos existentes no mercado, pelos organismos a eles sujeitos e uma margem de segurança relativamente aos efeitos colaterais que se pretende que seja cada vez maior. 
1.Departamento de Química e Bioquímica, Faculdade de Ciências de Lisboa, CiTecMat, Faculdade de Ciências de Lisboa Rua Ernesto de Vasconcelos, 1700 Lisboa, Portugal. 2. Departamento de Química e Bioquímica, Faculdade de Ciências de Lisboa, Rua Ernesto de Vasconcelos, 1700 Lisboa, CECF, Faculdade de Farmácia, Avenida das Forças Armadas, 1699 Lisboa, Portugal.

REFERÊNCIAS

1. E. Weinberg in "Principles of Medicinal Chemistry", 3a ed; W. Foye (Ed) W. Foyer (Ed), Lea Febinger, Philadelphia, 1990; p 731.

2. J. Heeres in "Medicinal Chemistry, the role of Organic Chemistry in Drug Research", $1^{\text {a }}$ ed S.M.Roberts, B.J.Price (Ed), Academic Press; London, 1985; p 249.
3. K. Richardson in "Medicinal Chemistry, the role of Organic Chemistry in Drug Research", 2a ed, C. R. Ganellin, S.M.Roberts (Ed), Academic Press,London 1993; p 257.

4. J. Bennett in" The Pharmacological Basis of Therapeutics", Goodman and Gilmans (Ed), $8^{\text {a }}$ ed., Pergamon Press, New York, 1990; p 1175.

5. C.A.Lyman., T.J. Walsh. Drugs,44, (1992), 9.

6. D.R.Bennett, Drug Evaluation - Annual Am.Med. Assoc., Milwaukee, (1991), 1979.

7. M.R. McGinnis, M.G. Rinaldi,.in "Antibiotics in Laboratory Medicine", $3^{\text {a }}$ ed,V. Lorian ed., Williams \& Wilkins, Baltimore; 1991; p.198.

8. R. Voet, J.G. Voet, in "Biochemistry", $2^{\mathrm{a}}$ ed., John Wiley \&Sons, Inc. USA(1995); p.690.
9. G.Petranyi, N.S. Ryder e A. Stutz, Science, 224, (1984).1239.

10. K.J. Barret-Bee, A.C. Lane e R.W. Turner, J.Med. Vet.Mycol., 24,(1986), 155.

11. M. Borgers, M. Van den Bossch, M. De Brabander, Am. J. Med. 74-1B, (1983). 2.

12. G. Willemsens, W. Cools, H. Van den Bossche, in "The Host Invader Interplay", H.Van den Bossch, ed., Elsevier, Amsterd;1980; p 691.

13. H. Van den Bossch, G. Willemsens, Arch. Int. Physiol. Biochem.,90, (1982), B218.

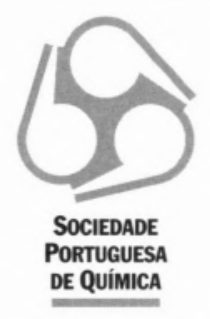

COLABORE COM A SOCIEDADE

\section{NÃO ATRASE O PAGAMENTO DAS SUAS QUOTAS}

\section{SPQ - QUOTAS}

\section{Sócio Efectivo .................... $6000 \$ 00$ \\ Sócio Estudante .................. $3500 \$ 00$ \\ Sócio Casal ..................... $9000 \$ 00$}

